\title{
$\operatorname{arCOS}$ DESIGN
}

\section{ou duas ou três palavras sobre a palavra design ou}

Frederico Guilherme Bandeira de Araujo (GPMC/IPPUR/UFRJ, Brasil) fredaraujo2048@gmail.com

UFRJ - Grupo de Pesquisa Modernidade e Cultura - GPMC/IPPUR Av. Pedro Calmon, 550 - Cidade Universitária, Rio de Janeiro

Ilha do Fundão, RJ, Brasil, CEP: 21941-917

Heitor Levy Ferreira Praça (GPMC/ IPPUR/UFRJ, Brasil)

heitorlevy2@gmail.com

UFRJ - Grupo de Pesquisa Modernidade e Cultura - GPMC/IPPUR Av. Pedro Calmon, 550 - Cidade Universitária, Rio de Janeiro

Ilha do Fundão, RJ, Brasil, CEP: 21941-917

Letícia Castilhos Coelho (GPMC/IPPUR/UFRJ, Brasil)

leticiaccoelho@gmail.com

UFRJ - Grupo de Pesquisa Modernidade e Cultura - GPMC/IPPUR Av. Pedro Calmon, 550 - Cidade Universitária, Rio de Janeiro Ilha do Fundão, RJ, Brasil, CEP: 21941-917 


\title{
ou duas ou três palavras sobre a palavra design ou
}

Resumo: Trata-se de uma reflexão livre sobre perspectivas políticas possíveis ao campo do design na sociedade contemporânea, constituindo-se de argumentações e narrativas alegóricas fundadas em Deleuze e Guattari, e Derrida. No ensejo de imaginar, ou mesmo inventar democracias outras, propugna, quase como um manifesto, um "desútil design" enquanto um design-devir que insista na contraposição à reiteração do Mesmo, e se constitua em tensão ao traço funcional-estético-ético dominante e mesmo crítico, como uma arte do insólito a instigar rasuras à sedutora e potente criatividade do capital.

Palavras-chave: design, política, narrativa.

\section{or two or three words about the word design or}

\begin{abstract}
Is a free reflection on possible political perspectives relating to the field of design in contemporary society, utilizing allegorical arguments and narratives based on Deleuze and Guattari, and Derrida. The opportunity to imagine or to create new democracies advocates - almost as a manifesto- for an "un-useful design": a becoming design that insists in counterpoint to the reiteration of the Same. This "un-useful design" constitutes itself in tension with dominant functional-aesthetic-ethical or critical lines of thought, as an art of the uncommon that provokes ruptures with capitalism's seductive and potent creativity.
\end{abstract}

Keywords: design; politics, narrative. 
O vazio entre os prédios imensos do centro da cidade parece saído de um sonho. Uma breve caminhada a leva para uma pequena praça, volteada por casas pequenas, simples e muito antigas. Poucas pessoas figuram aí nesse ambiente. Dentro de si, de modo bastante contrastante com a paisagem e agenciando uma tranquilidade incomum, a multidão habitual. Mais alguns passos, cruza a velha porta, adentra uma das casinhas. De pronto está num auditório, sentada à mesa de debates, com um microfone à sua frente. Definitivamente está sonhando. Está surpresa com essa mudança súbita e receia que lhe passem a palavra. Aquela velha neurose... diz pra si mesma. As caras, que pouco a pouco aparecem, preenchendo o auditório, lhe causam simpatia, mas esse sentimento é interrompido pelos ruídos de mãos aplaudindo. Não as vê nem sente, mas suspeita que suas próprias mãos participam da sinfonia de congratulação. Ato contínuo escuta seu nome e vê que todos os rostos se voltam em sua direção. Curiosamente, tem algo a dizer:

66

Falo de um lugar que invento agora como fora do campo disciplinar usualmente dito do 'design', independentemente de qual seja o significado atribuído a essa palavra. Externo, portanto, em minha construção de mim e dos outros de mim (vocês, no imediato deste momento), tanto à prática desse campo, como também à reflexão sobre ele. Faço-me aqui um outsider intruso para, no entanto, imediatamente ousar borrar essas aparentes fronteiras ou o dentro / fora do referido campo. Faço-me aqui agora design de um palavrório que designo como "desútil design".

Então comecemos essa fala, essa palavração, tomando o mote da mesa que diz: “... designers têm se deparado com a crescente complexidade que constitui as questões no mundo contemporâneo (...) À luz de uma sociologia das associações, também conhecida como teoria do ator-rede, designers têm sido estimulados a ativar um pensamento mais tentacular, reconfigurando a tradicional dimensão do projeto como um processo de "drawing things together". Caracterizado por um fazer mais aberto, experimental e especulativo, essas práticas cartográficas são capazes de potencializar outras narrativas e uma compreensão mais ampla dos diversos agenciamentos que compõem uma determinada questão. Esses pensamentos e práticas reticulares (...) estão, (...), intrinsecamente conectados com as novas tecnologias". [tendo isso em consideração, completa arguindo:] "Podem todas essas redes - de coisas e de representações das coisas - transformar extensa e intensivamente o modo de agir, participar e estar juntos 
nos espaços reais e virtuais, além dos "entre" espaços e pessoas, $e$ assim constituir uma democracia ampliada e renovada".

$\mathrm{O}$ apelo à criação ao modo de agenciamento coletivo como ato político parece-me aí incontornável. Não obstante, não penso que da democracia representativa, como está constituída e operando no mundo contemporâneo, mesmo nessa atualidade de tecnologia digital e formas de ação enredadas e enredantes, possa ser desdobrado algo radical e efetivamente novo.

Mas imagino possível a invenção de uma democracia outra, uma democracia da multiplicidade, das intensidades, da diferença, a partir do embate em todas as frentes, escalas, modos e formas contra o reinado do ser, do absoluto, da verdade universal atemporal. Um embate que, pra mim, deve ter por fulcro o campo da palavra enquanto palavra. No sentido de instituí-la, através dela mesma, como não mais do que expressão de agenciamentos entre o que estaria sendo designado como pessoas e coisas.

Tomando essa perspectiva, a questão de ordem mais geral que me coloco objetivamente para aqui refletir é a de como pensar a possibilidade da construção de uma democracia outra no que diz respeito a um domínio teórico-prático qualquer. No caso, em particular, ao domínio usualmente nomeado design. Não se trata, em meu entender, de fazer terra arrasada. Nem muito menos de supor que este, ou qualquer outro domínio vai fazer a revolução e instaurar alguma boa ordem ou certo caos libertário. Mas postulo algo que no mínimo procure não favorecer a reiteração do Mesmo. Que aposte, ainda que sem garantia ou certeza do que sucederá, na desestabilização poiética do discurso dominante oficial ou mesmo crítico. Então, pra sintetizar essa ousadia, digo: por um design rasurado, por um design outro, que procure não reiterar o que funda essa democracia que não mais permite que o gerenciar o poder do Mesmo. Por um design e uma democracia enquanto aposta na potência do que eu diria multiplicidade corpopalavra, potência a outros outros corpospalavras.

Nessa perspectiva imagino um design como atividade marcada pela ideia do desútil, assumindo essa palavra, ao modo de Manoel de Barros, não como a significar algo sem qualquer utilidade possível, mas como a sinalizar o que coloca em cheque o primado absoluto da função, como o que escapa ou rasura 
razões de eficiência, de precisão, de economia, de status, da estética de mercado, da ética da grande mídia, de chronos, da eficiência produtivista, do valor de troca, da razão operatória, do sentido de obra acabada. Desútil diz daquilo que, molecamente desobediente, aventureiro e desafiador em relação ao cânone apolíneo, é capaz de agenciar intensidades dionisíacas e assim abrir possibilidades a invenções outras, a compor o que seriam devires loucos aos agentes nas singularidades que se fazem no próprio agenciar. O desútil como paradoxo que desfaz dicotomias. Não determina nada, mas insiste e incide e (assim) intensifica, faz-se intensidade.

Um design desútil, desse modo, configuraria atividade que busca conceber e obrar coisas que, mesmo quando designadas por substantivos, procurem evidenciar o devir infinito de que não escapam e que pode ser expresso através de sentidos verbais de mise en abîme. A obra, em sua materialidade, nessa perspectiva não mais do que seria imaginada como dispositivo a infinitos aconteceres (agenciamentos com outras obras e natureza e singularidades) passíveis de atribuição de predicados lógicos, mas ao mesmo tempo imaginada como dispositivo passível de provocar poieticamente sentidos (acontecimentos) singulares e múltiplos.

Um desútil design como obração aberta infinita, nunca como obra acabada, totalizada, fechada em si mesma. Como o que porta a angústia da falta sem objeto faltante, da ausência sem ser ausente, da imprecisão brumosa naquilo que sugere a que serve. Desútil design como arte do insólito.

Nessa perspectiva, como dizer dessa arte do insólito em sua insolitude prática ou experiencial? Como falar de aconteceres e acontecimentos design?

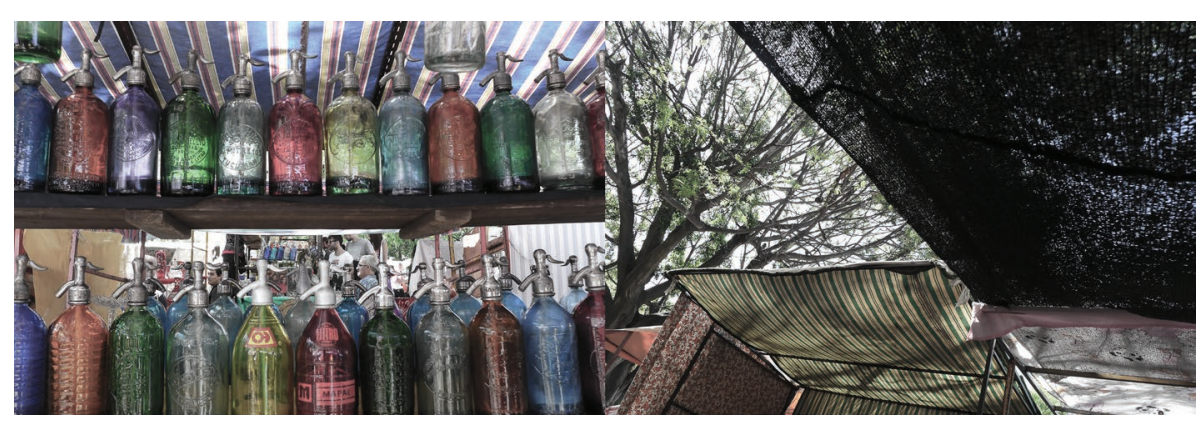

Figura 1. entre-tempo dito "um sábado em san telmo 1" (fonte: fotografias de Letícia Castilhos Coelho). 
, pouco depois, chego ao cômodo e há um objeto elegante que me entorta à primeira vista, ainda que facilmente analítico à minha razão operatória não consigo dizer nada a mim mesma, e nem há outro alguém por ali de casaco branco com certo temor e atração irresistível o toco e um calor rubro toma conta do que até aquele momento por comodidade digo: eu

vozes do outro lado emitem sons que se misturam e rodopiam como tornados no arizona e voo fazendo sinapses, tomada pelo que me afeta e impregna ruídos ásperos em meio aos quais constituo, como tentativa infrutífera de reconciliação de mim, uma expressão como palavra falada. e num estalo apolíneo sequencio analiticamente uma função e outras funções ao que percebo sensorialmente. para imediatamente cair em abismo tornando a palavra capturada verbo que ao mesmo tempo diz coisa e mim e outras de mim.

trata-se de um fazer-se pra lá e pra cá ao mesmo tempo, enrosco paradoxo de corpos sem dimensão mas febris e palavras e palavras outras palavras e durações indetermináveis em tempos que nem chegam a chegar e já se vão e temperaturas deslizantes e texturas carnívoras e narrativas paradoxais não descritivas e não ordenadas. atordoada balbucio a lotta bernardes: amareloásperorisonhoestonteante ou todas as cores, ou arco íris, ou simplesmente cor, cor, cor e textura branca. ela me olha entre surpresa e desassossegada.

talvez seja inefável, mas este fazer-se aqui agora, enquanto tentativa de dizer aquilo que neste momento nomeio como la fura dels baus ou fuerza bruta, sentido daquele acontecer, que lotta bernardes diria "coisa/tu” _que por pura incapacidade ou preguiça deste fazer, mas tentando ir além, renomeio dança ou encanto do abismo_, sentido que se desdobra outro sentido e que, também por falta de criatividade ou economia, qualifico neste instante como desmemória, e nomeio carinhosamente ariel ou rosa ou aidê ou isaura.

e saio de cena. 


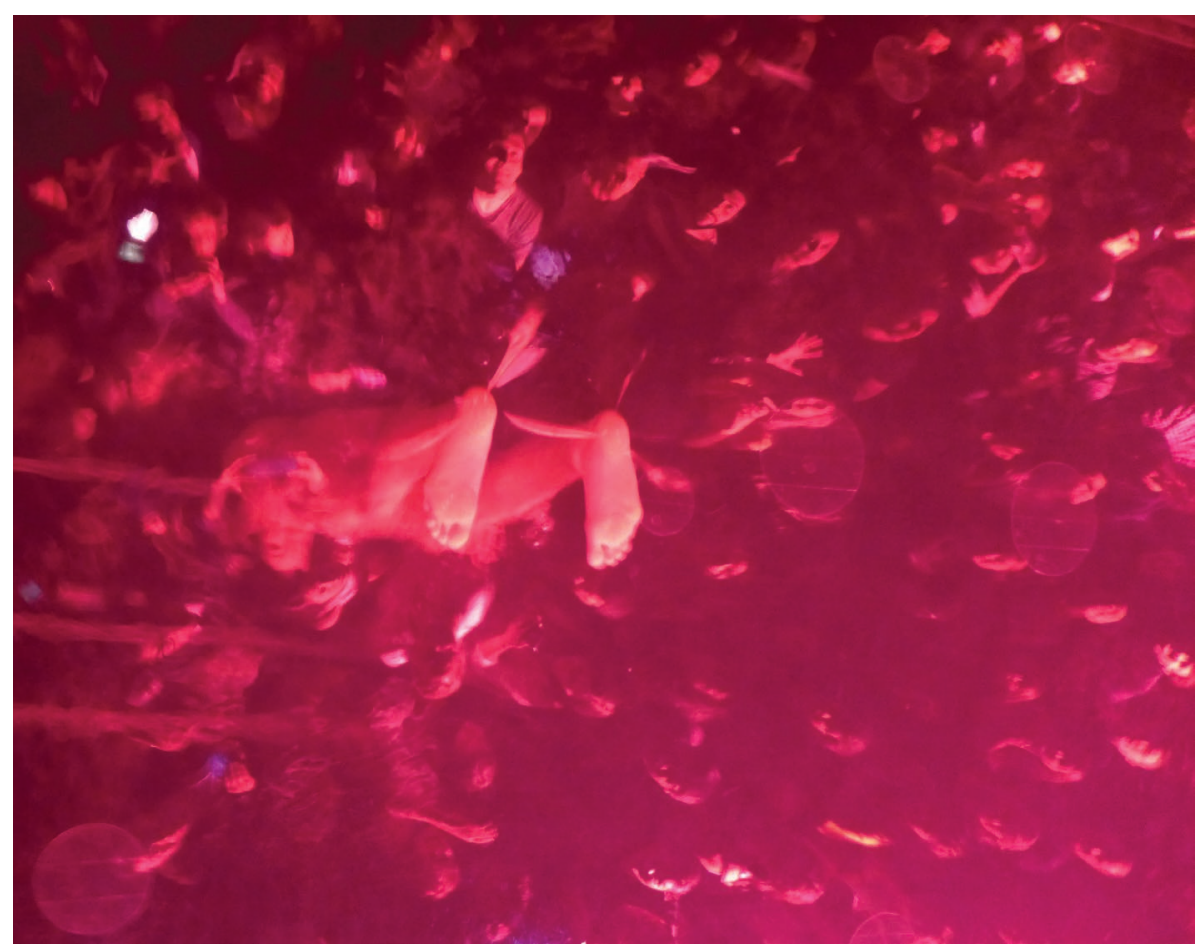

Figura 2. fuerza(s) bruta(s) ou outrxs de mim (fonte: fotografia de Letícia Castilhos Coelho durante o espetáculo Fuerza Bruta (Buenos Aires, novembro/2016)).

66

Na busca desse "como falar", penso numa narrativa design outro como expressão de desmemórias de aconteceres e acontecimentos como um duplo viés de um mesmo movimento: primeiro, em relação ao memoriar instituindo e navegando um tempo fora dos gonzos no que diz um acontecer design. Ou seja, negação da ideia de memória pautada num tempo natural e mesmo num tempo ideado, criado, humano, mas estruturado unicamente sobre a linha de Cronos: trilha que segue linearmente através de momentos sucessivos desde uma origem num suposto passado ao futuro destinado. Trilha totalidade que percorre um presente esgarçado composto por qualquer recorte de passado e futuro.

E também, no que mais interessa aqui nesta fala, marcando a dualidade paradoxal do tempo, em relação ao memoriar no que diz um acontecimento design, ou ao sentido de um design. Neste caso trata-se de um memoriar como desmemória que se agenciaria, sem nega-los, para além dos parâmetros reguladores do dentro / fora dos gonzos ou das dimensões sucessão, permanência e coexistência do tempo Cronos. Esse desmemoriar se agencia enquanto devir insistindo _temporalidade 
Aion_em presentes que nunca são, mas se fazem e refazem sem parar como incidência e insistência de uma tempofagia incessante que metaboliza futuro em passado. Síntese disjuntiva com Cronos em infinitude vertiginosa de presentes sem espessura, ainda que dotados de duração.

Uma narrativa de um acontecimento design, então, como sentido de um experienciar singular, nessa perspectiva não remeteria a qualquer passado mensurável suposto dado (de criação, de interações práticas, de usos), trazido por ato de lembrança de testemunho ao presente, e aí narrado; nem corresponderia a uma criação estéril (estéril porque dado arbitrário) de um presente esgarçado que engloba passado e futuro. Seria, em rasura a isso, um dizer enquanto agenciarnarrar em necessária, constante e sem início ou fim atualização de criação, como as marés. O ato de dizer design seria desse modo permanente poiésis. $\mathrm{O}$ agente desse desmemoriante dizer não seria um sujeito, mas pura singularidade, que não mais do que se faz enquanto tal através do próprio desmemoriar.

A narrativa do tempo no/do design outro seria a do tempo de sua trajetória enquanto acontecer (tempo da criação, de eventos, de passagens, de marcas de propriedade, de formas e modos de uso), e enquanto tempo do acontecimento narrativa que se faz fazendo-se (tempo sem espessura da afectação, com a duração do intenso enquanto vibração/reverberação/ sentido singular de um modo corpopalavra descronologizado). Tempo da experiência paradoxal de devir.

O objeto design, no sentido do aqui designado design outro, seria entendido como aquilo que aparece, superfície pura, não como aparência de uma suposta essência ou transcendência qualquer. Todavia, o que pode ser dito como o que aparece não é mais do que uma narrativa que assim se faz no próprio ato narrativo. E o que é dito como o sentido do que aparece na experiência do aparecer é o sentido que constitui o próprio aparecer simultâneo da coisa e do dizer que diz a coisa.

Objeto design outro concebido e dito então como Corpo sem Órgãos. A-funcionalidades rasurando funções evidenciadas em cada narrativa de um acontecer. Conectividades rizomáticas. Devir e cristalizações.

O objeto concreto de um design outro, destarte, não deixaria de poder ser dito como coisa, corpo, função, gênese, volume, 
cor, textura, dureza, resiliência, peso, forma, ao qual poderiam ser atribuídos predicados como belo, harmônico, equilibrado, politicamente correto, crítico, etc. Mas, o que marcaria seu caráter de design outro, seriam coisas de ordem distinta: sua concepção e elaboração de modo para além do funcional estético ético, de tal maneira que favoreça condições a instigar democraticamente borramentos à sedutora e potente criatividade do capital, que incorpora e desdobra a própria crítica aos descalabros que causa, ainda que não haja nenhuma garantia de que tal coisa se realize. De tal maneira então que favoreça acontecimentos singulares, multiplicidade, devir, aberturas de linhas de fuga inusitadas, alargamento do campo de possíveis comuns.

Acontecimentos fronteira entre corpos e linguagem.

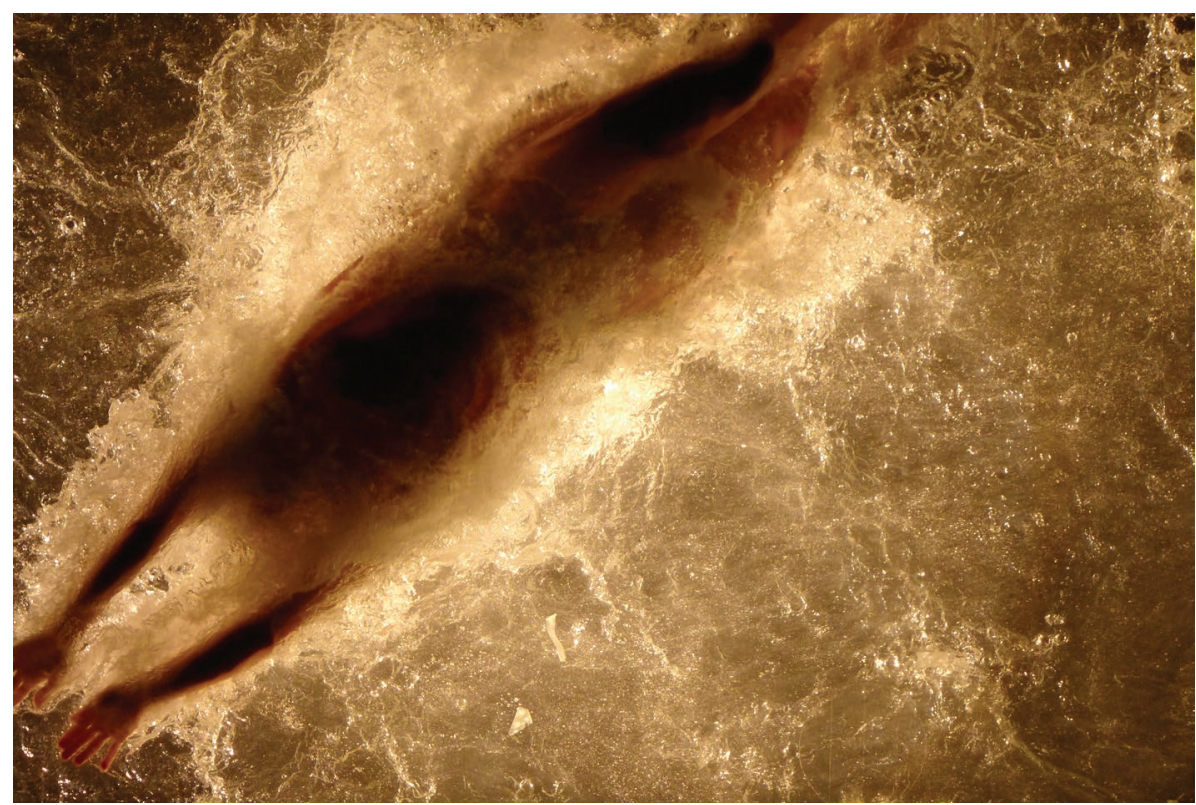

Figura 3. brutas fuerzas ou de corpos sem órgãos-e-sem palavras (fonte: fotografia de Letícia Castilhos Coelho durante o espetáculo Fuerza Bruta (Buenos Aires, novembro/2016)). 
a feira de móveis no sábado pela manhã, na rua tumultuada de sol e comida e gente colorida e cheiro de terra molhada.

desliza ágil e lentamente por entre poltronas de tafetá e móbiles de acrílico fuxia e luminárias de led. não precisa de nada mas seduz-se por certas taças de design ousado que, imagina, poderão somar forma ao breve prazer de gosto, cor e cheiro do vinho das noites cúmplices.

depois do chorinho se encanta com a rusticidade fake de móveis que supõe lindos à casa de campo que não tem

quase de partida bate os olhos num criado mudo simples, funcional e silencioso como todo criado mudo. mas este tem uma pequena e estranha reentrância, aparentemente inútil e desfuncional, a quebrar sua elegância de mordomo

fica a imaginar funções e mistérios de Poe. dá voltas em torno tateando o criado. pega seus óculos de perto. estou é ficando cego!

a melhor visão faz com que se interesse mais pela inesperada reentrância do móvel. no lado interno da dobra percebe umas ranhuras. identificação do fabricante, certamente. duas mulheres de batom vermelho também observam e a de vestido florido apaixonante exclama em tom pra se fazer ouvir: detalle más estapafurado!

curioso, fixa o olhar aproximando-se mais. as marcas parecem traços toscos feitos à canivete. contorcendo o corpo consegue posição que permite ver que se trata de uma escrita. "Ich han dich lib, joshua - Berlin 1933", sussurra pra si desajeitado tateando longínquas lições de Iídiche.

suas palavras caem como a luz em tardes de outono. senta-se no chão e torna-se abismo. leveza de amores que se fazem brisa no tempo. aspereza rude de dores e distâncias incontornáveis. amargor na boca. breve sorriso. olhar na superfície do dentro. pele.

ela o toca no ombro com delicadeza. vamos recolher os móveis, senhor. amanhã o designer estará aqui de tarde; se o senhor quiser saber sobre a peça... elecriadomudo na avidez do futuro que se faz incessante e imediatamente passado, devagar abre os olhos e levanta-se. corpospalavras haviam feito seu mais precioso trabalho.

noiteia. ele acontecendo outro. 


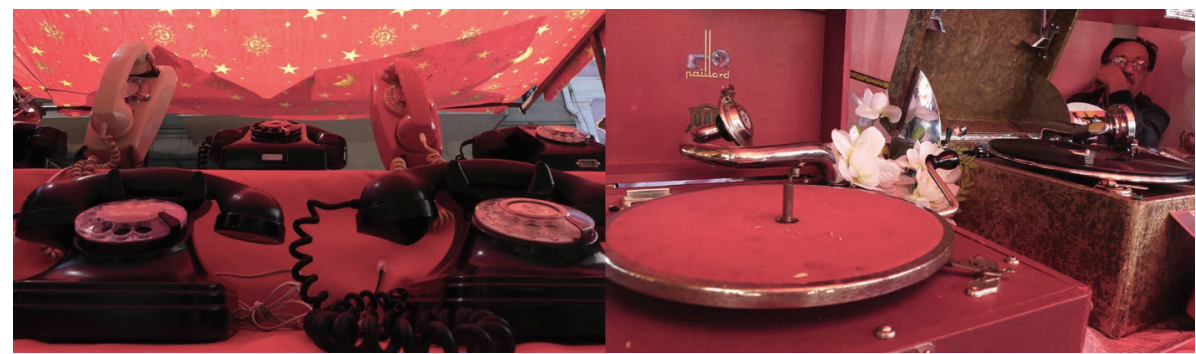

Figura 4. entre-tempo dito "um sábado em san telmo 2" (fonte: fotografias de Letícia Castilhos Coelho).

66

Objeto design rasurando suas próprias funções no tornar intensidade o exercício dessas mesmas funções, e operando como dispositivo a intensidades outras, inusitadas, singulares a cada relação. $\mathrm{O}$ ato criativo de projeto de tal tipo de design, entendido como trama de agenciamentos maquínicos e de enunciação coletiva, não se bastaria como processo dito de "drawing things together" (tipo de processo em relação ao qual a proposição da mesa se posiciona criticamente), processo operado por sujeitos racionais previamente (e posteriormente) dados e centrados. E nem mesmo se bastaria como ancorado num modo operativo de ator-rede, tão fértil a caminhos mais tentaculares e abertos ao design crítico contemporâneo, como aponta também a proposta da mesa. Não obstante a positividade desse modo operativo (ator-rede), o mais pertinente às ideias aqui inventadas de um design outro, de um desútil design seria a de um "agente-rizoma": aquele agente não sujeito, mas ecceidade (individuação sem sujeito) que se faz no próprio agenciar coletivo, trama diabólica de desejos e palavras, de corpospalavras, da incessante movida comerfalar.

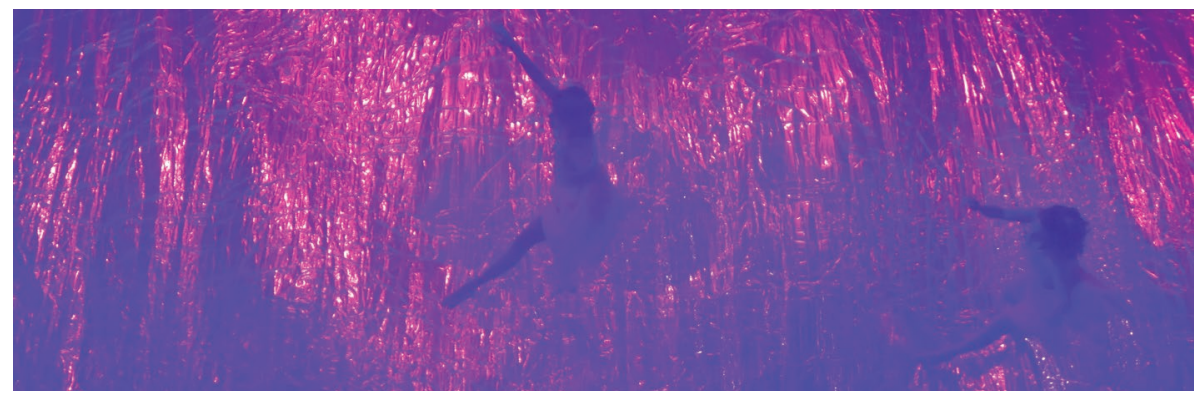

Figura 5. las fuerzas (ni tan) brutas ou da incessante movida comerfalar (fonte: fotografia de Letícia Castilhos Coelho durante o espetáculo Fuerza Bruta (Buenos Aires, novembro/2016)). 


\section{Referências}

BARROS, Manoel de. Livro sobre Nada. Rio de janeiro: Record, 2001.

BENJAMIN, Walter. Passagens. Belo Horizonte/São Paulo: Editora UFMG/ Imprensa Oficial do Estado de São Paulo, 2007.

DELEUZE, Gilles. Lógica do Sentido. São Paulo: Perspectiva, 1974.

DELEUZE, Gilles; GUATTARI, Felix. Mil Platôs.Capitalismo e esquizofrenia. Vol. 1. São Paulo: Editora 34, 1995.

. Mil Platôs. Capitalismo e esquizofrenia. Vol. 2. São Paulo: Editora 34, 1995. . Mil Platôs. Capitalismo e esquizofrenia. Vol. 4. São Paulo: Editora 34, 1997.

DERRIDA, Jacques [1971]. "Firma, acontecimiento, contexto". Márgenes de la filosofía. Madrid, Cátedra, 1989.

Salvo o nome. Campinas, SP: Papirus, 1995.

. Como no hablar. Y otros textos. Barcelona: Proyecto A Ediciones, 1997. . A farmácia de Platão. São Paulo: Iluminuras, 2005. 


\section{Como citar}

ARAUJO, F. G. B.; PRAÇA, H. L. F.; COELHO, L. C. ou duas ou três palavras sobre a palavra design ou. Arcos Design. Rio de Janeiro: PPD ESDI - UERJ. Edição Especial Outubro 2017. pp. 76-88. Disponível em: [http://www.e-publicacoes.uerj.br/index.php/ arcosdesign]

DOI: $10.12957 /$ arcosdesign.2017.30942

\section{(c) (1) (3)(9)}

A Revista Arcos Design está licenciada sob uma licença Creative Commons Atribuição - Não Comercial - Compartilha Igual 3.0 Não Adaptada. 